\title{
As Concepções de Currículo e suas Implicações no Discurso Geográfico
}

\author{
The Conceptions of the Curriculum and its Implications in the Geographical Speech
}

Las Concepciones de Currículo y sus Implicaciones en el Discurso Geográfico

\author{
Alberto Alexandre Lima de Almeida ${ }^{1}$ \\ Maria da Conceição Lima Vieira ${ }^{2}$
}

\begin{abstract}
RESUMO: O currículo se configura como um dos mais importantes campos de estudo no âmbito educacional. Para além de uma mera seleção de conteúdos, ele se constitui num elemento que impacta o próprio funcionamento da escola, tendo em vista o seu caráter político e pedagógico. Desta forma, este artigo se propõe a discutir, por meio de um estudo bibliográfico, a interface currículo/ensino de Geografia, a partir da análise das diferentes concepções que embasam a teoria do currículo, conforme Costa (1999), Goodson (2008) e Silva (2010), bem como suas implicações na sala de aula de Geografia. Para tanto, revisitamos as principais correntes de pensamento da Geografia, mediante as contribuições de Martins (2011), Oliveira (1994) e Tonini (2006), relacionando-as com o fazer pedagógico dos professores dessa disciplina, e também com a proposta curricular contida nos Parâmetros Curriculares Nacionais.
\end{abstract}

PALAVRAS-CHAVE: Currículo. Ensino. Geografia.

ABSTRACT: The curriculum configures itself as one of the most important fields of study in education. In addition to a mere selection of contents, it constitutes an element that affects the proper functioning of the school in view of its political and pedagogical character. In his way, this article proposes to discuss, through a bibliographical study, the curriculum / teaching interface of Geography, based on the analysis of the different conceptions that support the curriculum theory, according to Costa (1999), Goodson (2008) and Silva (2010), as well as its implications in the Geography classroom. To that end, we revisited the main currents of thought in Geography, through the contributions of Martins (2011), Oliveira (1994) and Tonini (2006), relating them to the pedagogical achievement of the teachers of this discipline, as well as to the curricular proposal contained in the National Curricular Parameters.

KEYWORDS: Curriculum. Teaching. Geography.

RESUMEN: El currículo se configura como uno de los más importantes campos de estudio en el ámbito educativo. Además de una mera selección de contenidos, se constituye en un elemento que impacta en el propio funcionamiento de la escuela teniendo en vista su carácter político y pedagógico. De esta forma, este artículo se propone a discutir, a través de un estudio bibliográfico, la interfaz currículo / enseñanza de Geografía, a partir del análisis de las diferentes concepciones que fundamentan la teoría del currículo, conforme Costa (1999), Goodson (2008) y Silva (2010), así como sus implicaciones en el aula de Geografía. Para ello, revisamos las principales corrientes de pensamiento de la Geografía, mediante las contribuciones de Martins (2011), Oliveira (1994) y Tonini (2006), relacionándolas con el hacer pedagógico de los profesores de esa disciplina, como también con la propuesta curricular contenida en los Parámetros Curriculares Nacionales.

PALABRAS CLAVES: Currículo. Enseñanza. Geografía.

\footnotetext{
${ }^{1}$ Mestre em Educação - Professor de Geografia do Instituto Federal do Rio Grande do Norte. alberto.almeida@ifrn.edu.br.

${ }^{2}$ Especialista em Educação- Assessora Pedagógica da Secretaria Municipal de Educação de NatalRN.mclvieira@hotmail.com.
} 


\section{INTRODUÇÃO}

As profundas transformações socioeconômicas, políticas e culturais vivenciadas pelo mundo contemporâneo, a partir das últimas décadas do século $\mathrm{XX}$, suscitaram a premente necessidade de se discutir os reflexos desse cenário no campo da educação. Tais transformações apresentam uma série de fatores que caracterizam o seu quadro sintomático: a crise do socialismo real, o recrudescimento dos conflitos étnico-nacionalistas, o declínio do fordismo e sua substituição pelo sistema de acumulação flexível, a e expansão das novas tecnologias da informação e comunicação. Todos esses acontecimentos já apontam indícios da emergência daquilo que Harvey (2010) denominou de "condição pós moderna", na qual emerge o culto ao espetáculo, a efemeridade e a mercadificação das formas culturais.

No que concerne à educação, tais transformações têm impactado de tal forma que apontam na perspectiva de se rever teorias, questionar saberes e redefinir valores. Nesse contexto, instala-se uma crise de paradigmas, na qual a própria verdade científica é relativizada e a concepção de ciência moderna é questionada.

Nesses termos, há uma sensação de mudança, de crise e de ansiedade em muitos locais de trabalho, nos quais, segundo Goodson (2008), uma das batalhas que está sendo travada diz respeito aos tipos de conhecimento que os trabalhadores são estimulados a adquirir em sua situação, como empregados.

Essa tensão na esfera educacional se espraiou pelos mais diversos campos de análise da moderna pedagogia, no que diz respeito às questões ligadas à metodologia, à avaliação, à interdisciplinaridade e, principalmente, quanto à questão do currículo enquanto categoria aglutinadora das citadas anteriormente. A esse respeito, Sacristan (2000) ressalta que o currículo faz da escola um determinado sistema social, na medida em que contribui para a sua instrumentalização.

Assim sendo, o objetivo desse artigo consiste em tecer considerações acerca das concepções de currículo que, de uma forma ou de outra, contribuíram para aprimorar o debate ora em questão, discorrendo sobre as implicações dessas concepções no discurso pedagógico dos professores de Geografia, face às transformações que também se processaram no seio desse componente curricular. 


\section{REVISITANDO AS CONCEPÇÕES SOBRE CURRÍCULO}

O vocábulo currículo deriva da palavra latina curriculum, que pode ser traduzido como "pista de corrida". Em que pese as mais diversas interpretações sobre a definição última de currículo, todas elas convergem para a ideia de que ele consiste em se determinar o tipo de conhecimento que deve ser ensinado, ou seja, qual saber deve ser considerado importante para fazer parte do currículo. A esse respeito, Silva (2010) enfatiza que o currículo é sempre o resultado de uma seleção, isto é, de um universo mais amplo de conhecimentos e saberes seleciona-se aquela parte que vai constituir, precisamente, o currículo.

Indissociavelmente ligada à questão anterior, um discurso sobre o currículo também versa sobre o tipo de ser humano que se deseja formar para a sociedade. Nesse contexto, o currículo não pode se restringir a uma mera escolha de conteúdos a serem ensinados; fazse necessário, também, relacionar esses conteúdos ao tipo de sociedade que está posta ou àquela que se almeja construir. Nesse contexto, Apple (2006, p. 83) enfatiza que "[...] o problema do conhecimento educacional, do que se ensina nas escolas, tem de ser considerado como uma forma de distribuição mais ampla de bens e serviços de uma sociedade".

Para discorrermos sobre as concepções de currículo, nos fundamentamos na classificação de Silva (2010), segundo a qual as teorias do currículo podem ser agrupadas em três categorias: as tradicionais, as críticas e as pós-críticas. Enquanto as teorias tradicionais enfatizavam a neutralidade do discurso sobre o currículo, as duas últimas desmistificam a análise de um currículo centrado na objetividade e dissociado das relações de poder.

\section{O Enfoque Tradicional Sobre o Currículo}

O estabelecimento do currículo como um campo especializado de estudos teve sua origem a partir das contribuições de John Bobbit (1876-1956), notadamente a sua obra intitulada: The curriculum. Conforme Silva (2010), nesse livro Bobbit propunha que a escola deveria funcionar tal qual uma empresa. Assim sendo, da mesma forma que uma indústria, o sistema educacional deveria especificar os resultados que pretendia atingir e, para isso, era necessário o estabelecimento de métodos para obtê-los, como também, criar instrumentos que permitissem a sua mensuração.

Nesse contexto, o sistema educacional deveria instituir objetivos, os quais, para serem alcançados, exigiriam a utilização de estratégias baseadas nas habilidades necessárias ao atingimento da eficiência. A mensuração da eficiência na escola se daria a partir da aplicação de testes e provas, de acordo com os objetivos pré-estabelecidos. Dessa forma, o 
currículo tradicional tecnicista procurava estruturar o planejamento escolar mediante o esquema: conteúdos $\rightarrow$ objetivos $\rightarrow$ metodologia $\rightarrow$ avaliação.

Em que pese algumas diferenças entre os arautos das teorias tradicionais do currículo, é comum a todos eles o entendimento de currículo centrado na ideia de organização e desenvolvimento. Sendo assim, a atividade científica de um especialista em currículo deveria se resumir a uma atividade burocrática.

Outro teórico identificado com as teorias tradicionais do currículo foi Ralph Tyler (19021994), que consolidou o modelo proposto por Bobbit, fundamentando o currículo em torno da ideia de organização e desenvolvimento. Para Tyler (1974), o currículo diz respeito aos objetivos educacionais perseguidos pela escola, os quais deveriam ser formulados a partir de um viés comportamentalista.

Convém ressaltar que esse modelo tradicional de currículo se constituiu em uma reação ao modelo clássico de educação, preponderante desde a Antiguidade Clássica até o Renascimento. Esse modelo, também chamado de humanista, enaltecedor das obras literárias e artísticas de herança grega e latina, não mais atendia às necessidades do homem moderno, tendo em vista a sua suposta inutilidade para fins laborais.

\section{O Currículo Sob a Perspectiva Crítica}

A partir da década de 1960, a concepção tradicional de currículo passa a ser questionada em diversas partes do mundo. A descolonização da África e Ásia, os protestos estudantis na Europa e o movimento feminista são exemplos de manifestações sociais e culturais que põem em xeque o stablishment.

Mediante esse contexto, surgem teorizações que vão de encontro às concepções tradicionais de currículo e, por que não dizer, de todo o sistema educacional. São as chamadas teorias críticas do currículo. Acusando o currículo tradicional de alienante e reprodutivista, os teóricos críticos propunham a análise do currículo a partir de uma ótica libertária, na qual se tornaria imprescindível desvelar as injustiças sociais inerentes ao capitalismo.

De acordo com autores como Althusser (1983), Apple (2006) e Silva (2010), a educação, enquanto aparelho ideológico do Estado teria como função legitimar o modo de produção capitalista, na medida em que transmitia valores e crenças que reforçavam os arranjos sociais existentes, qualificando-os como desejáveis e necessários. Segundo Moreira e Silva (2005, p. 8): 
relações de poder, o currículo transmite visões sociais particulares e interessadas, o currículo produz identidades individuais e sociais particulares. O currículo não é um elemento transcendente e atemporal ele tem uma história, vinculada a formas específicas e contingentes de organização da sociedade e da educação.

Essa relação entre a ideologia dominante e os saberes escolares encontra-se dissimulada em função do discurso de neutralidade vigente nos estabelecimentos educacionais, entretanto a vertente não manifesta do conhecimento disseminado nas instituições escolares compõe o que Jackson (1968) denominou de "currículo oculto". Ele seria constituído pelos aspectos do ambiente escolar que mesmo não fazendo parte do currículo oficial, contribuem, de forma implícita, para aprendizagens sociais relevantes. Entre esses aspectos, podemos citar as relações de autoridade, a organização do tempo-espaço na escola e os padrões de recompensa e castigo.

Convém ressaltar que, através do "currículo oculto", o que se aprenderia efetivamente na escola não seria apenas conteúdos, mas, principalmente, atitudes, valores e comportamentos que suscitam o ajustamento aos ditames da sociedade capitalista. Além disso, o currículo escolar desempenharia um papel importante na medida em que nos remeteria a uma seleção de conteúdos a serem ensinados nas escolas, num processo que reflete os interesses particulares das classes e grupos dominantes. Em outras palavras, aqueles conteúdos que pudessem suscitar uma postura crítica por parte do educando eram desconsiderados, declarados sem objetividade ou rotulados de "não científicos". No Brasil, tivemos um exemplo clássico desse processo quando do banimento das disciplinas de Sociologia e Filosofia da estrutura curricular do ensino de $1^{\circ}$ e $2^{\circ}$ graus durante o período da ditadura militar (1964-1985). Nessa perspectiva, Apple (2006, p. 130) afirma:

O currículo oculto das escolas serve para reforçar as regras básicas que envolvem a natureza do conflito e seus usos. Ele impõe uma rede de hipóteses que, quando internalizadas pelos alunos, estabelece os limites de legitimidade. Esse processo realiza-se não tanto pelos exemplos explícitos que demonstram o valor negativo do conflito, mas pela quase total ausência de exemplos que demonstrem a importância do conflito intelectual e normativo em diferentes áreas do conhecimento.

Mesmo não pautando suas obras sobre a temática específica do currículo, Freire (1996) nos traz algumas reflexões que contribuem para o debate no campo curricular, na medida em que discorre sobre o papel de coadjuvante atribuído ao aluno no enfoque tradicional. Segundo ele, mediante essa perspectiva, o aluno se converte num receptáculo cuja principal função é absorver os conteúdos ensinados pelo professor, se constituindo num agente passivo no processo de ensino-aprendizagem. Além disso, questiona o caráter meramente reprodutivista da escola ao enfatizar que: "A educação é uma forma de 
intervenção no mundo. Intervenção que além do conhecimento dos conteúdos bem ou mal ensinados e/ou aprendidos implica tanto o esforço de reprodução da ideologia dominante quanto o seu desmascaramento" (FREIRE, 1996, p. 110).

Ainda do ponto de vista das teorias críticas do currículo, há que se destacar a perspectiva fenomenológica que deslocou o foco das investigações no campo do currículo das categorias teóricas abstratas e estruturais (ideologia, modo de produção e dominação) e passou a dar ênfase à subjetividade das experiências pedagógicas e curriculares.

O discurso fenomenológico refuta a estruturação tradicional do currículo em disciplinas, tendo em vista que elas se prendem a conceitos teóricos e abstratos. Assim sendo, o que realmente importa é a própria experiência do educando ou educador; os elementos fornecidos pela sua vida rotineira e cotidiana. Segundo Werner e Da Rosa (2007, p. 140):

A fenomenologia aponta para um currículo no qual se deixariam de lado tópicos tradicionais dos livros textos e se daria um direcionamento ao estudo para temas que fazem parte da vida cotidiana dos estudantes, envolvendo situações nas quais se fazem presentes tanto alunos como o próprio professor. Nestas atividades a busca é pela essência da experiência de vida descrita e não pela apropriação do significado do conceito envolvido, pelo menos não na forma de conceito científico.

Michael Young (1915-2002), um dos expoentes da Nova Sociologia da Educação, movimento surgido na Inglaterra no começo da década de 1970, trouxe importantes contribuições para as análises críticas do currículo e sua relação com a dimensão do poder instituído em uma sociedade. Para ele, o currículo é o resultado de um processo de conflito em torno de quais conhecimentos devem constituí-lo. Nesse contexto, a seleção e organização dos conteúdos obedeciam aos princípios de distribuição dos recursos econômicos e sociais mais amplos.

A perspectiva do "currículo em rede" também se apresenta como uma das vertentes que compõem as teorias críticas do currículo. Essa concepção procura romper o modo de organização dos saberes de forma fragmentada e pulverizada, tão característica do currículo tradicional. Para os teóricos que propõem essa organização curricular, a complexidade do mundo moderno não pode mais ser analisada à luz do fracionamento do conhecimento, sob pena de conduzir ao mecanicismo e ao reducionismo, os quais são incapazes de viabilizar as soluções para os problemas do nosso tempo. A esse respeito, Morin (2002, p. $40-41$ ) enfatiza que:

Nestas condições, as mentes formadas pelas disciplinas perdem suas aptidões naturais para contextualizar os saberes, do mesmo modo que para integrá-los em seus conjuntos naturais. O enfraquecimento da percepção do 
global conduz ao enfraquecimento da responsabilidade (cada qual tende a ser responsável apenas por sua tarefa especializada), assim como ao enfraquecimento da solidariedade (cada qual não sente mais os vínculos com seus concidadãos).

Muitos outros teóricos trouxeram importantes contribuições para a análise sobre uma teoria crítica do currículo, todavia os limites impostos pelo presente artigo não permitem uma análise de suas obras. Bourdieu e Passeron (1975), Giroux (1986) e Bernstein (1996) procuraram relacionar o arranjo educacional existente à formação social dominante, se contrapondo à postura tecnicista do currículo tradicional.

\section{As Teorias Pós- críticas do Currículo}

Enquanto as teorias críticas colocaram na pauta de discussões sobre o currículo as categorias ideologia e poder, coube às teorias pós-críticas deslocar o eixo de reflexões para a questão do discurso e seus enlaces com o campo do currículo. Para tanto, são incorporadas novas categorias de análise que vão desde a concepção de representação, até a de cultura e de identidade.

Sob a ótica dos teóricos pós-críticos, as desigualdades de gênero e de raça eram ignoradas pelos defensores da perspectiva crítica, a quem acusavam de só observarem o mundo pelas lentes da luta entre as classes sociais e do determinismo econômico, vilipendiando os conflitos de natureza cultural.

A vertente multiculturalista do currículo advoga que as diferenças culturais são determinadas, em última instância, pelo discurso socialmente produzido, ou seja, a partir de representações que se validam e legitimam de acordo com as relações de poder existentes na sociedade. Entre os autores que enaltecem a importância de um currículo com viés multiculturalista na escola, podemos destacar Santos (2005), Costa (1999) e Santomé (1997).

$\mathrm{Na}$ perspectiva multiculturalista, o currículo é visto como um lugar privilegiado dos processos de subjetivação e de circulação de narrativas, aqui vistas como práticas modeladoras da "realidade", a qual é moldada segundo os interesses dos grupos com maior exercício de poder. Discorrendo sobre o papel das narrativas num currículo multiculturalista, Costa (1999, p. 63) infere que:

Voltando a acentuar que não se tratará nunca de identidades 'verdadeiras', essencialistas e totalizantes, mas de representações socialmente construídas, não-fixas e históricas, essas narrativas poderiam adentrar os currículos escolares, substituindo os relatos formulados do ponto de vista do colonizador pelos relatos de afirmação dos grupos colonizados que contam suas histórias particulares sobre a experiência da opressão e sobre os sonhos e lutas por igualdade e liberdade. 
A organização do "currículo por competências" é uma das tendências que encontra ressonância em muitas publicações no meio acadêmico. Segundo seus defensores, entre os quais destacamos Pereira (2005), Costa (2004) e Perrenoud (1999), mais do que transferir conhecimentos é papel da escola viabilizar o desenvolvimento de competências, as quais permitiriam aos discentes o enfrentamento de situações que se apresentam ao longo de sua vida. Nesse caso, observa-se uma tendência em se imprimir uma dimensão mais prática ao currículo. De acordo com Perrenoud (1999, p. 21) "[...] pensar em termos de competência significa pensar a sinergia, a orquestração de recursos cognitivos e afetivos diversos para enfrentar um conjunto de situações que apresentam analogias de estrutura".

Para os defensores dessa linha de pensamento, durante o processo de ensinoaprendizagem o indivíduo mobiliza uma série de esquemas cognitivos que permitem a sua utilização em diferentes e novos contextos. Dessa forma, o domínio de competências e a apreensão de conteúdos estão interligados, ou seja, antes de se constituírem como ideias antagônicas, ambas apresentam características de imbricação.

Nos últimos anos, tem se destacado a ideia de "currículo integrado", principalmente no nível de ensino médio. Os institutos federais de educação, ciência e tecnologia apresentam experiências que visam integrar disciplinas de caráter técnico com as disciplinas de formação geral (Geografia, História, Biologia etc.). De acordo com o projeto político pedagógico dessas unidades de ensino, o objetivo é a formação do homem omnilateral. Ao domínio do conhecimento técnico deve haver a superposição do conhecimento de mundo e de sociedade, com vistas ao desenvolvimento de uma consciência crítica e de uma formação cidadã. A esse respeito, Ciavatta (2005, p. 85) escreve que:

A ideia de formação integrada sugere superar o ser humano dividido historicamente pela divisão social do trabalho entre a ação de executar e a ação de pensar, dirigir ou planejar. Trata-se de superar a redução da preparação para o trabalho ao seu aspecto operacional, simplificado, escoimado dos conhecimentos que estão na sua gênese científicotecnológica e na sua apropriação histórico-social.

São muitas as concepções de currículo que permeiam o processo educativo. Essas que foram arroladas anteriormente se constituem em algumas das vertentes teóricas que fecundam no campo curricular. As implicações de tais concepções para a sala de aula de Geografia é o enfoque sobre o qual nos deteremos a seguir. 


\section{O ensino de Geografia e as Proposições Sobre o Currículo}

Desde quando foi alçada à condição de saber científico, nos idos do século XIX, a Geografia esteve vinculada a diferentes correntes de pensamento, as quais, além de instigarem discussões de natureza epistemológica, influenciaram o fazer pedagógico dos professores dessa disciplina.

As correntes (ou escolas) determinista e possibilista dominaram o cenário geográfico ao longo do século XIX, estendendo-se até as primeiras décadas do século XX. Apesar de algumas diferenças no campo epistemológico, elas costumam ser arroladas no que convencionou-se denominar de "Geografia tradicional". Enquanto a primeira, amplamente difundida no meio acadêmico alemão, analisava o ser humano como produto do meio natural, os possibilistas, enquanto corrente dominante no meio acadêmico francês, atribuíam ao ser humano a capacidade de interferir no meio ambiente. Ao analisar as implicações do determinismo geográfico no discurso pedagógico, Tonini (2006, p. 39) ressalta que:

"A Geografia escolar, ao estabelecer que, para melhor governar era imprescindível conhecer melhor o quadro natural, direcionou discurso para descrever os povos via natureza, pois esta era o elemento de normatização, já que todas as relações de poder eram explicadas pela natureza".

Por sua vez, o possibilismo geográfico procurou abolir qualquer forma de determinação, adotando a ideia de que a ação humana é marcada pela contingência. $A$ natureza era, então, considerada como fornecedora de possibilidades para que o homem a modificasse. Nesse sentido, Tonini (2006, p. 54) ressalta que:

O homem, para o possibilismo geográfico, inscreve-se apenas como uma variável que modela e humaniza as paisagens geográficas. Essa visão negligencia, portanto, o processo pelo qual os homens dão significados para suas práticas e o modo como abstraem e transferem tais significados para outros contextos.

Em que pese as suas especificidades, o determinismo alemão e o possibilismo francês compunham a vertente tradicional do pensamento geográfico devido ao caráter essencialmente descritivo, baseado numa análise do espaço geográfico que ficava limitado ao reducionismo empirista. Dessa forma, era competência da Geografia questionar "o quê" e "como" se manifestavam os fenômenos no espaço geográfico, escamoteando a discussão sobre o "porquê" da existência desses fenômenos.

Em nível pedagógico, os reflexos dessas correntes estavam expressos numa disciplina essencialmente mnemônica, cujo objetivo precípuo era a memorização de conteúdos, os quais deveriam ser assimilados sem passar pelo crivo da criticidade e, no momento oportuno, serem cobrados através de testes ou provas. Acerca dessa postura 
pedagógica, ressalta-se que "[...] os professores e alunos são treinados a não pensar sobre o que é ensinado e sim, a repetir pura e simplesmente o que é ensinado". (OLIVEIRA, 1994, p. 28).

Em consonância com o postulado acima descrito, o currículo de Geografia também se apresentava com uma roupagem tradicional, na medida em que seus conteúdos estavam voltados para a descrição dos tipos de clima e de vegetação, a relação das atividades econômicas de um lugar ou a caracterização dos elementos populacionais de uma dada área, em suma, fatos que conferiam à ciência geográfica o estigma de saber inútil e desinteressado. Nesse contexto, infere-se que "[...] os currículos plenamente tradicionais descrevem o espaço geográfico. Um espaço criado a partir das premissas positivistas de neutralidade e objetividade, espaço esse que é uma abstração e, portanto, não retrata a realidade" (CARVALHO, 2007, p. 29).

A partir de meados do século $X X$, a ciência geográfica passa por um movimento de renovação que coloca em xeque as concepções tradicionais de geografia. $O$ advento da escola anglo-saxônica, também chamada de "quantitativa" ou "teorética", se contrapõe ao modelo tradicional ao inferir métodos matemáticos ao processo de análise geográfica, ao mesmo tempo em que recorre a procedimentos da informática para o estudo dos fenômenos espaciais.

Levada ao âmbito da sala de aula, essa corrente da Geografia se pautava pelo exacerbado emprego de gráficos, tabelas e fórmulas matemáticas, redundando numa geometrização do espaço sem, contudo, abandonar o caráter descritivo e acrítico da Geografia tradicional. Segundo Moreira (1982, p. $44-45)$ :

Assim, em vez da descrição da paisagem, toma seu lugar a matematização da paisagem. Em vez da descrição da morfologia da paisagem, toma seu lugar uma rigorosa tipologia de padrões espaciais. Em vez da pesquisa de campo, toma seu lugar o computador. Em vez da descrição subjetiva, toma seu lugar a objetividade descritiva da linguagem matemática. Por conseguinte, foi grande o salto da Geografia: do positivismo para o neopositivismo. De um lugar para o mesmo.

Dessa forma, podemos observar que a Geografia quantitativa manteve estreitas relações com as teorias tradicionais do currículo, tendo em vista que mantinha a visão técnica de currículo no tocante à organização e seleção de conteúdos, sem fazer relações com as estruturas econômicas, políticas e sociais que interferem na sua construção.

Foi só a partir da década de 1970 que o movimento de renovação do ensino de Geografia promove uma ruptura mais radical com os postulados da Geografia tradicional. Muitos geógrafos, em suas reflexões teóricas, passaram a utilizar o materialismo histórico e dialético como método de interpretação da realidade espacial, possibilitando o surgimento 
da chamada "Geografia crítica". Esses geógrafos não escondiam a sua insatisfação com o caráter descritivo e mnemônico dessa disciplina, dos seus pressupostos metodológicos e de sua compartimentação em ramos estanques (Geografia física, Geografia humana, Geografia econômica etc.).

Os geógrafos críticos denunciavam que a Geografia tradicional era um instrumento a serviço do capital e que não propiciava uma análise reflexiva sobre o espaço geográfico, além de não ter condições de dar conta das novas perspectivas do ensino e da sociedade, pois, de acordo com Martins (2011, p. 65):

Essa nova conjuntura conduz a uma reformulação dos pressupostos teórico-metodológicos do ensino da Geografia com o objetivo de levar os professores a superar metodologias que se centram na transmissão mecânica dos conteúdos, com a memorização de inúmeras informações, o que não contribui para levar os alunos a uma compreensão das relações estabelecidas num contexto histórico, social e espacial dos fenômenos geográficos.

Ao introduzir temas como sistemas socioeconômicos, políticas de urbanização e reforma agrária ao cenário geográfico, o movimento de renovação crítica da Geografia passa a desvelar as contradições existentes no espaço geográfico, as quais passam a ser vistas como produto das próprias contradições do capitalismo, o qual procura, no âmbito da escola, reproduzir valores e regras que o legitimem.

Nesse contexto, a Geografia crítica apresenta aproximações com as teorias críticas do currículo, notadamente aquelas de inspiração marxista, não apenas pelo fato de incorporar ao seu objeto de estudo categorias de cunho econômico e social, mas também ao denunciar que a Geografia tradicional ignorava o seu caráter de reprodutora de um saber dissociado dos arranjos estruturais da sociedade.

Nos últimos anos, em que pese a sua grande aceitabilidade no meio acadêmico, a Geografia crítica de inspiração marxista, passou a dividir o palco do cenário geográfico com concepções humanísticas, especialmente a vertente conhecida como "Geografia cultural". Para os geógrafos culturalistas, a globalização tem acentuado as diferenças culturais entre os lugares, permitindo que as particularidades do espaço sejam vistas como representações de suas práticas culturais. Segundo Tonini (2006, p. 74), “[...] na paisagem estão impressas as marcas culturais, por meio de linguagem cujos significados pertencem a uma determinada cultura".

Ao contrário dos geógrafos críticos, os geógrafos culturalistas não centralizam as suas análises na produção do espaço a partir da luta de classes, o que, segundo estes, privilegia apenas a dimensão econômica, opacionando as relações de poder que envolvem as diferenças culturais. Para eles, reconhecer apenas as diferenças de classes sociais implica em desconsiderar as demais dimensões da vida humana. Influenciados pela fenomenologia, 
alguns geógrafos culturais consideram o universo das representações como ponto de partida para o conhecimento geográfico. Para Gil Filho (2005, p. 57):

"Uma Geografia das representações é uma Geografia do conhecimento simbólico. Assume as representações sociais como ponto de partida para uma Geografia Cultural do mundo banal, da cultura cotidiana, do universo consensual impactado pelo universo reificado da ciência e da política".

As aproximações entre a Geografia cultural e a corrente multiculturalista do currículo são inegáveis. Além de considerar as diferenças culturais como importante categoria de análise, ambas também apontam na perspectiva de uma análise mais subjetiva dos fenômenos estudados. Em nível escolar, elas podem ser traduzidas pela valorização dos estudos do continente africano, tanto nas aulas de Geografia quanto na disciplina de História, e também na inserção de elementos do cotidiano nos estudos de natureza geográfica.

Também vale ressaltar as contribuições que a disciplina de Geografia pode dar a uma concepção de currículo integrado, tendo em vista que, enquanto ciência que procura examinar e explicar a estreita relação e interdependência entre elementos naturais e sociais, ela não pode prescindir de manter uma relação de dialogicidade com os demais ramos do conhecimento, sob pena de refugiar-se num isolacionismo que a remeterá a uma inelutável condição de saber inútil e descompromissado com a formação do ser humano em sua plenitude. Nessa perspectiva, Hammes, Forster e Chaigar (2011, p. 134) preconizam:

A compreensão de que o mundo, fragmentado nas diferentes disciplinas, é um só, aponta para a necessidade de se estabelecer o diálogo como fonte de inspiração para entender a complexidade da perspectiva interdisciplinar, visto que é através do diálogo que todo o ser humano é brindado com a oportunidade de pronunciar a sua palavra.

Um currículo integrado pode se constituir num importante passo para reconhecer a complexidade do conhecimento, ao mesmo tempo em que contribui para a formação omnilateral do ser humano e desmistificar o caráter de neutralidade atribuída ao saber científico. Nessa perspectiva, dada a sua natureza epistemológica, a Geografia reúne todas as condições para estimular a integração curricular nas diversas dimensões e modalidades de ensino.

\section{O Discurso Pedagógico dos Parâmetros Curriculares Nacionais de Geografia}

Enquanto documento oficial que referencia a ação pedagógica de professores de todo o país, os Parâmetros Curriculares Nacionais dos anos finais do Ensino Fundamental tem 
sido objeto de importantes discussões no meio acadêmico, sejam no sentido de se tecer críticas ao seu arcabouço teórico, seja no sentido de se questionar a forma como se procedeu a sua elaboração. Por outro lado, não são poucos os professores que se identificam com as premissas do documento e fundamentam a sua prática docente com base nas proposições nele contidas.

Visando garantir a existência de um conteúdo mínimo para o Ensino Fundamental, os PCN de Geografia se propõem a trazer reflexões críticas ao corpo discente, propiciando ao aluno a possibilidade de compreender o seu papel no conjunto de relações entre a sociedade e a natureza. Para tanto, trabalha com diferentes noções de espaço e tempo, abrangendo os variados fenômenos sociais, culturais e naturais de cada paisagem, enfatizando o caráter processual de construção do espaço geográfico. Conforme afirma o documento:

A Geografia tem por objetivo estudar as relações entre o processo histórico na formação das sociedades humanas e o funcionamento da natureza por meio da leitura do lugar, do território, a partir de sua paisagem. Na busca dessa abordagem relacional, trabalha com diferentes noções espaciais e temporais, bem como com os fenômenos sociais, culturais e naturais característicos de cada paisagem, para permitir uma compreensão processual e dinâmica de sua constituição, para identificar e relacionar aquilo que na paisagem representa as heranças das sucessivas relações no tempo entre a sociedade e a natureza em sua interação (BRASIL, 1998, p. 26).

No que concerne ao seu referencial teórico, o documento evidencia um caráter de ecletismo que, se por um lado pode revelar uma ausência de concepção filosófica, por outro, traduz a pluralidade de concepções que permeia o fazer pedagógico dos professores espalhados por todos os quadrantes do território nacional. Ao se constituir como um documento de referência a todos os professores, independentemente de sua orientação político-ideológica, os PCN não poderiam assumir uma concepção filosófica única, sob o risco de marginalizar ou vilipendiar o trabalho pedagógico de uma parcela considerável da classe docente. Admitindo que não exista neutralidade em qualquer produção acadêmica, concordamos com Straforini (2011, p. 55) quando reitera:

Pensar o currículo na perspectiva da recontextualização por hibridismo não significa deixar de lado a análise crítica sobre o papel do Estado, de seu poder de produção de discursos hegemônicos, mas recontextualizá-lo diante das ações de seus praticantes, em especial dos professores e das escolas que carregam histórias pedagógicas de lutas e resistências nem sempre alinhadas às políticas curriculares de governo.

Os PCN apontam na perspectiva de promover a interdisciplinaridade e a transversalidade, ao propor que os conteúdos sejam trabalhados por meio de grandes eixos 
temáticos e através de temas transversais, tendo em vista o "[...] reconhecimento da necessidade de incorporar tanto a ideia da flexibilização quanto a interdisciplinaridade no tratamento com o conteúdo dessa área" (BRASIL, 1998, p. 32).

É evidenciado ao longo do documento que os eixos temáticos se constituem em elementos subsidiadores que auxiliam na escolha dos conteúdos a serem trabalhados pelos professores, os quais possuem autonomia tanto para adaptá-los à realidade de sua escola, como também para os objetivos que propõem em sua disciplina.

Os eixos temáticos não representam um programa de curso e tampouco uma proposta curricular a ser seguida de forma dogmática. Eles representam subsídios teóricos que devem ser entendidos como ponto de partida, e não de chegada, para o professor trabalhar os conteúdos da Geografia no ensino fundamental (BRASIL, 1998, p. 37).

No que tange aos temas transversais, estes procuram estabelecer uma maior aproximação entre os conteúdos das diferentes disciplinas e também visa inserir, na sala de aula, a discussão sobre questões de urgência social, tendo em vista uma formação pedagógica voltada para o pleno exercício da cidadania. Nesse sentido, o documento elenca seis temas a serem tratados sob a forma da transversalidade: Ética; Pluralidade Cultural; Meio Ambiente; Trabalho e Consumo; Saúde e Orientação Sexual.

Dado o seu caráter epistemológico, o conteúdo programático da Geografia reúne todas as condições de estabelecer um diálogo profícuo com esses temas, contribuindo assim para uma formação omnilateral do educando. Dessa forma, a Pluralidade Cultural pode ser discutida em temas como "Divisão Regional do Brasil"; Trabalho e Consumo em temas como "Industrialização" ou "Globalização"; Orientação Sexual em "População Brasileira"; Saúde em "Problemas Urbanos"; Meio Ambiente em "Domínios Naturais do Brasil" ou "Impactos Ambientais Globais". A Ética permeia discussões como "Trânsito e Meios de Transporte" ou "Problemas Urbanos", entre outros.

Convém salientar que os exemplos supracitados são apenas uma pequena amostra de situações nas quais o componente curricular de Geografia pode auxiliar no sentido de propiciar uma intervenção pedagógica pautada na transversalidade. As realidades de cada escola são diferentes, e os momentos e as condições oportunas para encaminhar um trabalho dessa natureza variam em função das características inerentes a cada ambiente de aprendizagem. Dessa forma, cabe ao professor, numa relação dialógica com os seus alunos, estabelecer o entrelaçamento entre Temas Transversais e conteúdos de Geografia, buscando uma intervenção pedagógica que promova o desenvolvimento do senso críticoparticipativo dos educandos. 
A homologação da Base Nacional Comum Curricular do Ensino Fundamental (BNCC), em dezembro de 2017, tem o intuito de instituir um documento que sirva como referência para a construção dos currículos de todas as redes públicas do país. Todavia, Isso não significa que a Base exclua os demais documentos oficiais, entre os quais os PCNs, mas que dialogue com eles, consolidando uma necessidade historicamente situada, que é o estabelecimento e a organização progressiva das aprendizagens essenciais de toda a Educação Básica.

No que concerne à Geografia, a BNCC estabelece que a grande contribuição dessa disciplina consista em "[...] desenvolver o pensamento espacial, estimulando o raciocínio geográfico para representar e interpretar o mundo em permanente transformação e relacionando componentes da sociedade e da natureza" (BRASIL, 2017, p. 358). Para tanto, o documenta aponta a necessidade de se garantir a apropriação de determinados conceitos que viabilizem a apreensão do conhecimento e o convívio em sociedade.

Convém salientar que, a partir da data de sua homologação, foi estipulado o prazo de dois anos para que a BNCC venha a ser implantada em todo o território nacional. Dessa forma, uma análise mais aprofundada das implicações que tal documento acarretará no currículo de Geografia é um percurso que se abre a todos aqueles imbuídos em aprimorar os debates de natureza geográfica.

\section{CONSIDERAÇÕES FINAIS}

As concepções de ensino de Geografia guardam estreitas relações com o currículo dessa disciplina, o qual, por sua vez, não pode ser dissociado das condições socioeconômicas, políticas e culturais que marcam determinado momento histórico. É através dessa relação dialética que se estabelecem as políticas de currículo que norteiam os documentos oficiais que tratam dessa questão. Nesse sentido, o currículo não pode ser compreendido como um artefato provido de neutralidade e construído sobre bases eminentemente técnicas, sob pena de opacionarmos a dimensão social do processo educativo e cristalizarmos concepções pedagógicas que refletem uma concepção estática do real.

A interface entre currículo e conteúdos de Geografia se constitui num terreno fértil para a proliferação de discussões no meio acadêmico. O enredo dicotômico - ciência da natureza $x$ ciência da sociedade ou geografia física x geografia humana -, que tem acompanhado o discurso geográfico ao longo da história, encontra ressonância no campo do currículo, na seleção de conteúdos, no fazer pedagógico dos professores e na própria concepção de educação por parte destes últimos. 
Essas discussões ganham um novo palco para debates a partir da recente aprovação da Base Nacional Comum Curricular (BNCC). Este documento normativo se propõe a referenciar a reformulação dos currículos da Educação Básica dos estados e municípios. A despeito das críticas feitas à forma como se deu a sua aprovação, somente a partir de sua efetiva implementação é que será possível fazer uma análise mais profunda dos limites e das possibilidades desse documento.

Muitos são os caminhos que podem pautar o ensino de Geografia e suas composições curriculares. Não foi objetivo deste artigo, indicar qual seria o mais apropriado para nortear o fazer pedagógico dos professores de Geografia. Porém, em nosso horizonte, se coloca um imperativo premente: instigar o desejo e a paixão de aprender, não só para interagir com o conhecimento, mas também para promover a inexorável transformação social por todos nós almejada.

\section{REFERÊNCIAS}

ALTHUSSER, L. Aparelhos ideológicos de Estado. Rio de Janeiro: Graal, 1983. APPLE, M. Ideologia e currículo. Porto Alegre: Artmed, 2006.

BERNSTEIN, B. A estruturação do discurso pedagógico. Petrópolis: Vozes, 1996. BOURDIEU, P.; PASSERON, J. C. A reprodução. Rio de Janeiro: F. Alvez, 1975. BRASIL. Ministério da Educação. Secretaria de Educação Fundamental. Base nacional comum curricular: ensino fundamental. Brasília, 2017.

BRASIL. Ministério da Educação. Secretaria de Educação Fundamental. Parâmetros curriculares nacionais: ensino fundamental. Brasília, 1998.

CARVALHO, M. I. Fim de século: a escola e a Geografia. ljuí: Unijuí, 2007.

CIAVATTA, M. A formação integrada: a escola e o trabalho como lugares de memória e de identidade. In: FRIGOTTO, G.; CIAVATTA, M.; RAMOS, M. (Org.). O ensino médio integrado: concepção e contradições. São Paulo: Cortez, 2005. p. 83 - 105.

COSTA, A. Quatro questões sobre a noção de competências na formação de professores: o caso brasileiro. Revista de Educação, Campinas, n. 12, v. 2, p. 95-106, 2004.

COSTA, M. V. Currículo e política cultural. In: 0 currículo nos limiares do contemporâneo. Rio de Janeiro: Ed. DP e A, 1999. p. 37 - 68.

FREIRE, P. Pedagogia da autonomia: saberes necessários à prática educativa. São Paulo: Paz e Terra, 1996.

GIL FILHO, S. F. Geografia cultural: estrutura e primado das representações. Espaço e Cultura, Rio de Janeiro, n. 19-20, p. 51 - 59, 2005.

GIROUX, H. Teoria crítica e resistência em educação. Petrópolis: Vozes, 1986. GOODSON, I. As políticas de currículo e de escolarização. Petrópolis: Vozes, 2008. HAMMES, C. C.; FORSTER, M. M. S.; CHAIGAR, V. A. M. Formação de professores, integração curricular e a Geografia: o lugar escola como espaço de acontecimento. In: 
TONINI, I. M. et al. (Org.). O ensino da Geografia e suas composições curriculares. Porto Alegre: UFRGS, 2011. p. 121 - 143.

HARVEY, D. Condição pós-moderna: uma pesquisa sobre as origens da mudança cultural. São Paulo: Loyola, 2010.

JACKSON, P. Life in classroom. New York: Rinehart and Winston, 1968.

MARTINS, R. E. M. W. A trajetória da Geografia e seu ensino no século XXI. In: TONINI, I. M. et al. (Org.). $O$ ensino da Geografia e suas composições curriculares. Porto alegre: UFRGS, 2011. p. 61 - 75.

MOREIRA, A. F. B; SILVA, T. T. (Org.). Currículo, cultura e sociedade. São Paulo: Cortez, 2005.

MOREIRA, R. O que é Geografia. São Paulo: Brasiliense, 1982.

MORIN, E. Os sete saberes necessários à educação do futuro. São Paulo: Cortez; Brasília: UNESCO, 2002.

OLIVEIRA, A. U. Situação e tendências da Geografia. In: ensino de Geografia. São Paulo: Contexto, 1994. p. 24 - 29. (Org.). Para onde vai o

PEREIRA, M. O currículo por competências: a construção de um instrumento de verificação do desenvolvimento das aprendizagens, mediador da cooperação entre professores e psicólogos da educação. Revista da Escola Moderna, Lisboa, n. 23, p. 5 - 43, 2005.

PERRENOUD, P. Construir competências desde a escola. Porto Alegre: Artmed, 1999. SACRISTAN, J. G. O currículo: uma reflexão sobre a prática. Porto Alegre: Artmed, 2000. SANTOMÉ J. Interação cultural e aprendizagem. Lisboa: Fundação Calouste Gulbenkian, 1997. Textos de educação.

SANTOS, B. S. Dilemas do nosso tempo: Globalização, multiculturalismo e conhecimento. Educação \& Realidade, Porto Alegre, v. 26, n. 1, p. 13 - 32, 2005.

SILVA, T. T. da. Documentos de identidade: uma introdução às teorias do currículo. Belo Horizonte: Autêntica, 2010.

STRAFORINI, R. O currículo de Geografia das séries iniciais: entre conhecer o que se diz e o vivenciar o que se pratica. In: TONINI, I. M. et al. (Org.). 0 ensino da Geografia e suas composições curriculares. Porto alegre: UFRGS, 2011. p. 41 - 59.

TONINI, I. M. Geografia escolar: uma história sobre seus discursos pedagógicos. ljuí: Unijuí, 2006.

TYLER, R. W. Princípios básicos de currículo e ensino. Porto Alegre: Globo, 1974.

WERNER, C. T.; DA ROSA, C. A. Currículo e fenomenologia: limites e possibilidades no ensino experimental da Física. Revista Iberoamericana de Educación, Madri, n. 43, p. 133 - 146. 2007.

Recebido: abril de 2017. Aceito: abril de 2018. 